NASA Technical Memorandum 102545

\title{
Studies of Mechano-Chemical Interactions in the Tribological Behavior of Materials
}

Kazuhisa Miyoshi

Lewis Research Center

Cleveland, Ohio

Prepared for the

8th International Conference on Thin Films sponsored by the American Vacuum Society San Diego, California, April 2-6, 1990 


\title{
STUDIES OF MECHANO-CHEMICAL INTERACTIONS IN THE TRIBOLOGICAL \\ BEHAVIOR OF MATERIALS \\ Kazuhisa Mi yoshi \\ National Aeronautics and Space Administration \\ Lewis Research Center \\ Cleveland, Ohio 44135
}

\begin{abstract}
SUMMARY
Mechano-chemical interaction studies can contribute to our understanding of wear and friction of materials. Specific examples of experimental results relative to the subject are discussed. There are two parts to this paper: one part describes the synergistic effect of corrosion and wear of iron sliding on sapphire in sulfuric acid, and the other part describes the effect of surface films on the wear and friction of plasma-deposited diamondlike carbon (amorphous hydrogenated carbon) films in sliding contact with silicon nitride. The concentration of acid $(\mathrm{pH})$ is an important factor in controlling the iron loss caused by wear-corrosion processes in sulfuric acid. The mechanical action can cause chemical reactions to proceed much faster than they would otherwise. The diamondlike carbon (DLC) films are shown to behave tribologically much like bulk diamond. In a dry nitrogen environment, a mechano-chemical reaction produces a substance which greatly decreases the coefficient of friction. In a moist air environment, mechano-chemical interactions drastically reduce the wear life of DLC films and water vapor greatly increases friction.
\end{abstract}




\section{INTRODUCTION}

I am pleased to contribute this invited paper to the session on Coating Resistance to Erosion, Corrosion, and Severe Environments. This paper provides a review of some of our recent research relative to the subject and examples of our results.

The studies fall into two parts. The first part includes wear and friction of iron in sliding contact with aluminum oxide (sapphire) in various concentrations of sulfuric acid $[1,2]$. Aluminum oxide has been considered for use in contact with iron because it has greater wear and corrosion resistance than does the metal. Since this conference is concerned orimarily with thin films, the second part of this study deals with the wear and friction of OLC films, otherwise known as "amorphous hydrogenated carbon $(a-C: H)$ " [3]. The films were grown on silicon nitride substrates using plasma chemical vapor deposition at $30 \mathrm{kHz}$. Sliding friction experiments were conducted in both dry nitrogen and moist air environments to determine the environmental effects on resistance to wear and friction of the DLC films in sliding contact with silicon nitride.

Chemical reactions occurring during the mechanical interactions of metals and nonmetals, both in bulk and coating form, can alter the surface activity of these materials as well as altering their micromechanical properties.

Tribological properties such as adhesion, friction, deformation, wear, and lubrication of solids and coatings in contact are extremely dependent on the chemical and physico-chemical changes of materials caused by mechanical energy $[4-6]$.

Corrosion has been recognized as an important variable in the wear and friction of metals [7]. A synergistic effect between corrosicn and wear in tribological components such as aerospace bearings is serious and expensive and 
causes major problems [8,9]. Rolling elements tend to fail at random intervais from corrosion, wear, contamination, or handling damage long before fatigue initiates spalling. Corrosion and wear are major causes of rejection of aircraft turbine engine bearings. Cryogenic turbopump bearings in current and future rocket engines, such as in the space shuttle main engine, also require the use of much improved corrosion- and wear-resistant bearings without any tradeoff in material durability [8].

A most important fact of the wear-corrosion phenomena of metals is that mechanical wear and corrosion both depend on surface deposits and films [1]. Resistance to corrosion is often the result of some type of film forming on the metal. Mechanical wear can destroy such films. Alternatively, wear could develop better corrosion-resistant films by producing new surfaces. Furthermore, the coefficient of friction is, like wear and corrosion resistance, highly sensitive to surface films. Thus, the destructive alteration of the metal caused by both chemical and mechanical actions during sliding in a corrosive solution will be discussed in the first part of this paper.

Hard coatings with a low coefficient of friction such as DLC films have become more and more interesting for applications in mechanical devices $[10,11]$. The high wear resistance and dry lubricating properties of DLC films make them well suited for bearings where oils and greases cannot be employed [10]. With carbonaceous materials, such as graphite and diamond, various investigators have observed that the atmosphere alters the nature of the chemical and mechanical properties of the material surfaces $[12-16]$. There is a very fundamental interrelationship between the mechano-chemical interactions and tribological responses. As these properties are directly 
related to the subject, they will be discussed in the second part of this paper.

2. WEAR AND FRICTION OF IRON IN A CORROSIVE LIQUID ENVIRONMENT

It is well known that iron usually corrodes rapidly in nonoxidizing acids. However, if the oxidation is strong enough, the iron surface may become passivated by a protective oxide layer. Sulfuric acid is, in relation to iron, a typical nonoxidizing acid with an active anion.

To examine the interaction of sulfuric acid corrosion and mechanical wear of iron, sliding friction experiments were conducted with elemental iron riders (hemispherical pins with a tip radius of $3.2 \mathrm{~mm}$ ) sliding on aluminum oxide (sapphire) flats in aerated sulfuric acid at concentrations ranging from very dilute $\left(7 \times 10^{-5} \mathrm{~N}\right.$; i.e., $\left.4 \mathrm{ppm}\right)$ to very concentrated ( 96 percent) acid. The experiments were conducted with a load of $2.5 \mathrm{~N}$ and at a sliding velocity of $90 \mathrm{~mm} / \mathrm{min}$ at room temperature. The iron rider was made to traverse on the surface of aluminum oxide flat. The motion was reciprocal. Each experiment lasted $60 \mathrm{~min}$. Thus, the rider passed over the flat 540 times $(270$ times each way) during an experiment. The experiments were done in air, so the acid was standardized in the aerated condition.

Figures 1 and 2 present wear and friction results of iron riders in contact with aluminum oxide (sapphire) flats in aerated sulfuric acid with concentrations ranging from dilute $\left(7 \times 10^{-5} \mathrm{~N}, 4 \mathrm{ppm}\right)$ to concentrated $(35.6 \mathrm{~N}$, 96 percent) at a load of $2.5 \mathrm{~N}$ for $60 \mathrm{~min}$. At very dilute sulfuric acid concentrations ( 4 to $12 \mathrm{ppm}, 7 \times 10^{-5}$ to $2 \times 10^{-4} \mathrm{~N}$ ), both wear and friction were highly variable. A complex surface deposit formed on the surface of iron. It is recognized as a mixture of divalent and trivalent iron hydroxide, iron oxides, iron oxyhydroxides $[17,18]$. There was also x-ray photoelectron spectroscopic evidence that iron sulfate was part of the built-up layer [19]. 
This deposit was weak and brittle and was not a protective, passivating film. The thick oxidation product formed in the wear area was cracked extensively by the interfacial sliding action. Some of the deposit broke from the wear area and appeared as wear debris. Thus, formation and failure of the deposit that consisted of iron hydroxides, iron oxides, iron oxyhydroxides, and iron sulfate gave erratic and often relatively high friction and great loss of iron in the wear area. The buildup of the corrosion product was not limited to the wear area but also occurred in a region well outside the wear area [1].

At slightly higher sulfuric acid concentrations $(0.005$ to 0.5 percent, $10^{-3}$ to $\left.10^{-1} \mathrm{~N}\right)$, the loss of metal in the wear area was at a minimum, and there was little evidence of a buildup of corrosion products on the wear area and outside it when the wear areas were examined using optical and scanning electron microscopy.

Iron losses in the wear areas increased sharply from the value at a 5-percent (1.O-N) acid concentration to a maximum at a 30-percent (7.5-N) acid concentration (Fig. 1). The maximum metal loss occurred with iron at the 30-percent (7.5-N) sulfuric acid concentration.

At 50- to 75-percent (15- to 23-N) sulfuric acid concentrations iron losses in the wear areas dropped markedly. The reduction in the wear rate is caused by the formation of passivating films.

At a 96-percent $(35.5-N)$ acid concentration iron losses in the wear area increased from the value for a 75-percent acid concentration to a second maximum at the 96-percent acid concentration. The relatively high iron loss is caused by the destruction of the passivating films. Sliding action smeared the wear surface and removed the passivating films. 
Over the acid concentration range of 5 to 96 percent the coefficients of friction were low (Fig. 2). Even at a 30-percent acid concentration the highest wear rate was associated with low coefficients of friction.

To compare the wear data presented in Fig. I with corrosion behavior, the dependence of the rate of corrosion of iron on the sulfuric acid concentration is shown in Fig. 3 [18]. The rate of corrosion with an increase in acid concentration rises exponentially in dilute solutions of sulfuric acid; however, at about 47- to 50-percent acid concentrations a maximum rate of corrosion is reached, after which it decreases, and for 70- to 100-percent acid concentrations the rate of corrosion is very low. With the appearance and increase in the monohydrate (100-percent sulfuric acid) of excess sulfur trioxide $\left(\mathrm{SO}_{3}\right)$, the rate of corrosion again increases, giving a second maximum corresponding to approximately 18 to 20 percent excess $\mathrm{SO}_{3}$. With a further increase in $\mathrm{SO}_{3}$ content, however, it again decreases.

When compared with the wear data (Fig. 1), the wear behavior of iron in sulfuric acid is generally similar to the corrosion behavior of iron in sulfuric acid (Fig. 3); however, the maximum wear rate in the wear-corrosion process is reached at about a 30-percent sulfuric acid concentration, while the maximum corrosion rate in the corrosion process is reached at about a 50-percent concentration. There is a significance in the differences (Figs. 1 and 3).

The dependence of wear rate (Fig. 1) and corrosion rate (Fig. 3) of iron on the concentration of sulfuric acid can be explained as follows: A maximum rate of wear at 30 percent and of corrosion at 50 percent must correspond to the maximum activity of sulfuric acid - i.e., the minimum pH. In dilute solutions, $\mathrm{pH}$ is an inverse function of hydrogen ion concentration; thus, an increasingly low or negative $\mathrm{pH}$ is associated with sulfuric acid concentrations 
up to about 30 percent ( $F$ ig. 4 , refs. 18 and 20). At higher concentrations, the hydrogen ion concentration decreases while pH again increases. The maximum concentration of active hydrogen ions according to the data available (Fig. 4) corresponds to about a 30-percent sulfuric acid concentration. This maximum concentration corresponds to the wear maximum of iron in the wear-corrosion process. In other words, the wear maximum corresponds to the maximum activity of sulfuric acid. In the corrosion process, however, there is a discrepancy between the first corrosion maximum and the maximum hydrogen ion concentration. This discrepancy can be fully explained by a decrease in the actual concentration of the acid near the corroding surface [18]. The discrepancy in the chemical reaction in the two processes (i.e., corrosion process and wearcorrosion process) is due to the influence of the mechanical energy caused by sliding. In other words, the discrepancy in the coordinates of the maximum rate of dissolution of iron is due to the influence of the mechanical energy induced by sliding. The chemical reaction is mechanically excited in the wearcorrosion process.

The reduction in the rate of wear and the rate of corrosion of iron (Figs. 1 and 3 ) in the more concentrated sulfuric acid ( 70 to 80 percent) is determined by the oxidizing action of concentrated sulfuric acid $\left(\mathrm{H}_{2} \mathrm{SO}_{4}\right)$ and the possibility of attaining passivity by the formation of passive cprobably oxide) films.

The second corrosion maximum in the corrosion process with an excess of $\mathrm{SO}_{3}$ ( $\mathrm{Fig} .3$ ) and the higher wear rate of 96 -percent acid concentration in the wear-corrosion process (Fig. 1) can be interpreted as destruction of the protective oxide films. 


\section{WEAR AND FRICTION OF OIAMONDLIKE CARBON FILMS}

The material studied in this section is diamondlike carbon (DLC). OLC films can be formed on different substrates by ion-beam deposition, ion-beam sputtering, and plasma deposition of gaseous hydrocarbons $[3,21]$. In this investigation, DLC films were grown on silicon nitride substrates by means of plasma chemical vapor deposition at $30 \mathrm{kHz}$ [21].

To examine the tribological properties of OLC films made by different deposition powers, sliding friction experiments were conducted with DLC films deposited on silicon nitride flats in contact with hemispherical silicon nitride riders (1.5-mm radius). The experiments were conducted in both dry nitrogen and humid air environments with a load of $1 \mathrm{~N}$ (hertzian contact pressure, $910 \mathrm{MPa}$ ) and at a sliding velocity of $8 \mathrm{~mm} / \mathrm{min}$ at room temperature. The specimen rider was made to traverse the surface of the OLC film. The motion was reciprocal. The DLC films were subjected to multipass sliding by the silicon nitride riders. The DLC films on the silicon nitride flat

substrates were approximately $0.06 \mu \mathrm{m}$ thick. The silicon nitride used for flat substrates and hemispherical riders was hot-pressed [3]. Reference experiments for wear and friction were also conducted with a single-crystal (111) diamond in contact with silicon nitride riders in both dry nitrogen and humid air environments.

\subsection{OLC Films}

OLC films are generally hard, semitransparent materials with properties that can be controlled by the deposition parameter settings, which in turn determine the amount of hydrogen contained in the films (e.g., Fig. 5). Figure $5(a)$ shows the nuclear reaction analyses data on hydrogen concentration $[3,22]$. The hydrogen concentration in the plasma-deposited OLC films decreases slightly with increasing deposition power from 25 to $300 \mathrm{~W}$. The hydrogen 
concentrations are in the 7.2 to $7.7 \times 10^{22} / \mathrm{cm}^{3}$ range, which gives an approximate value of 0.8 for $x$ in the formula $\mathrm{CH}_{x}$.

The argon ion etching rate of the DLC films is shown as a function of deposition power in Fig. 5(b). An inverse relationship is observed between the argon ion etching rate and the deposition power. The etching rate drops from 80 to $50 \mathrm{~nm} / \mathrm{min}$ when the deposition power is increased from 25 to $300 \mathrm{~W}$. This suggests that films grown at higher powers are denser than those grown at lower powers.

The microhardness data measured for the DLC films on a silicon nitride substrate at various deposition powers are presented in Fig. 6 . The microhardness increases as the deposition power increases. Thus, it appears that a decrease in hydrogen concentration is accompanied by an increase in film density and/or $c-c$ bondings and in hardness.

\subsection{Comparison Between DLC Films and Bulk Diamond}

DLC films behave tribologically much like the bulk diamond:

(1) The friction of both DLC films and the bulk diamond is generally low.

(2) In a dry nitrogen environment, mechano-chemical interactions during sliding alter the friction behavior of both DLC films and the bulk diamond similarly.

(3) Water vapor markedly influences the friction behavior of both DLC films and the bulk diamond.

Figures $7(a)$ and (b) present typical plots of the coefficient of friction for plasma-deposited DLC films at low (50 W) and high $(250 \mathrm{~W})$ deposition power as a function of the number of repeated passes in both dry nitrogen and humid air environments. Comparative data obtained with a single-crystal (111) diamond are also presented in Fig. 8. The coefficient of friction values 
given in figs. 7 and 8 are typical, and the trends with number of passes are reproducible.

With the 50-W plasma-deposited DLC films, the coefficient of friction was generally found to increase with increasing number of passes (Fig. $7(a)$ ). This increase, however, was small in a dry nitrogen environment even after it had been in contact with the rider for about 10000 passes. For the DLC films deposited at various deposition powers (50 to $300 \mathrm{~W}$ ), the low-density film deposited at 50 whas the lowest initial coefficient of friction 10.08 to 0.09) in the dry nitrogen environment. The value of the initial coefficient of friction was similar to that of the single-crystal (111) diamond shcwn in Fig. 8. The initial friction of the diamond in contact with silicon nitride was low (0.08) in dry nitrogen.

For the 250-W plasma-deposited DLC films (Fig. $7(\mathrm{~b})$ ), although the coefficient of friction increased with increasing number of passes for about 10 passes in the dry nitrogen environment, it generally decreased between 10 and 10000 passes. The DLC films behave much like the bulk diamond. The decrease in friction of the DLC films is similar to the decrease in friction of the single-crystal (111) diamond (Fig. 8). At 1000 passes and above, the coefficients of friction for the 250-W plasma-deposited DLC films became very low but variable $(0.1$ to 0.01$)$. The friction of the bulk diamond also became very low $(0.07$ to 0.01$)$ at 1000 passes and above. The drastic decrease in friction of both DLC films and the bulk diamond at 1000 passes and above could be due to the generation of a substance, probably a hydrocarbon rich layer [23]. In other words, mechano-chemical and tribo-chemical interations produce the reaction product and lead to drastic decreases in friction behavior of both denser DLC films and the bulk diamond at 1000 passes and above. 
The friction characteristics of the DLC films made by different deposition powers are separated into two types. With the relatively lower density DLC films deposited at 50 to $150 \mathrm{~W}$ power, the first type of friction characteristics shown in Fig. $7(a)$ was generally observed. The second type (Fig. $7(b)$ ) was observed primarily with the denser DLC films deposited at 200 to $300 \mathrm{~W}$ power.

\subsection{Water Vapor Effect}

An important constituent of the environment in affecting DLC film wear and friction is water vapor. Water vapor resides mainly on the surface of DLC films no matter if it was introduced as cold water, hot water, or steam [24]. Water is merely filling the valley regions of surface irregularities of DLC films. Furthermore, surface micropores (voids) of DLC films provide a strong tension for these very thin water layers.

The sliding friction experiments described in section 3.2 were also conducted in humid laboratory air environments. The results are presented in Figs. 7 and 8 . When compared with the coefficients of friction obtained in dry nitrogen, the coefficients of friction obtained in humid air for both OLC films and the bulk diamond were generally much higher. Water vapor greatly increases friction.

With the 50-W olasma-deposited DLC film, the sliding action in the humid air environment caused a breakthrough of the $f i l \mathrm{~m}$ and removed it from the sliding contact area at about 1000 passes. On the other hand, in dry nitrogen the 50-W plasma-deposited DLC film did not wear off the substrate even after it had been in contact with the rider for about 10000 passes. The DLC film is susceptible to water vapor: In particular, the water vapor greatly affects the wear life of the film. This suggests that much of the film wear vas due to a corrosive attack by the condensed moisture adsorbed on the micropores and on 
the valleys of surface irregularities of the DLC film. In the presence of water vapor, the mechano-chemical interactions reduce the wear life of DLC films.

The 250-W plasma-deposited DLC film did not wear off the substrate in humid air or in dry nitrogen even after it had been in contact with the rider for about 10000 passes.

At 1000 passes and above, the friction data are extremely interesting for both denser plasma-deposited DLC film at $250-W$ power and bulk diamond (Figs. $7(b)$ and $(8)$ ). The data indicate that, in the presence of water vapor, there is no drastic decrease in the friction with increasing number of passes, and the coefficients of friction remain constant with an increasing number of passes. On the other hand, the coefficients of friction decreased drastically in the dry nitrogen environment. This brings out another interesting point. In the presence of water vapor, the product of the mechano-chemical reaction (discussed in section 3.2 ) is probably dissolved in the water vapor residing on the surface of the DLC film.

Thus, in the presence of water vapor, which resides mainly on the surface of DLC and fills DLC surface micropores, friction increases greatly and mechano-chemical interactions reduce the wear life of low-density DLC films. 3.4. Graphitized DLC

When a OLC film is thermally annealed at $700^{\circ} \mathrm{C}$ in vacuum $\left(10^{-8}\right.$ to $10^{-9}$ torr), the surface chemistry changes greatly [3]. These chemical changes can alter the wear and friction behavior of DLC films.

Figure 9 presents the friction data for an annealed DLC film deposited at $300 \mathrm{~W}$ in sliding contact with silicon nitride riders in dry nitrogen and humid air environments. The results show an interesting feature: up to 100 passes the initial coefficients of friction in humid air were lower than those 
obtained in dry nitrogen. These results are contrary to those obtained for asdeposited OLC films (discussed in sections 3.2 and 3.3 ). This behavior of DLC films in humid air is similar to that of bulk graphite in that a certain amount of water seems to be required to show low friction [12 - 14]. Water vapor is necessary for the good lubrication of graphite. Thus, the annealed surface of the DLC film deposited at $300 \mathrm{~W}$ has very graphitic friction behavior.

Beginning at 200 passes ( $F i g .9$ ), the coefficient of friction decreases as the number of passes increases in dry nitrogen, while in humid air it increases. At 1000 passes and above, the coefficients of friction in dry nitrogen become lower than those obtained in humid air. This suggests that for this range the silicon nitride rider breaks through the graphite superficial layer and comes in contact with the bulk DLC film. When this occurs, the friction behavior is similar to that of the as-deposited DLC (Fig. $7(b)$ ) and the bulk diamond (Fig. 8) discussed in section 3.2. Again, there are the two interesting observations at 1000 passes and above. First, in dry nitrogen mechano-chemical interactions lead to a drastic decrease in the friction of OLC film; second, in humid air the presence of water vapor does not cause any decrease in friction with an increasing number of passes.

With the annealed OLC film shown in Fig. 9, the sliding action caused a breakthrough in the DLC film and removed it from the sliding contact area at about 14500 passes in humid air and at about 35100 passes in dry nitrogen. Even with the superficially graphitelike DLC film, the wear life of the film in humid air was reduced by a factor of about 2 as compared with that in dry nitrogen. 


\section{CONCLUDING REMARKS}

There are two parts in the paper: one part mainly describes the synergistic effect of corrosion and wear of iron in sulfuric acid, and the other deals with the effect of surface films on the wear and friction of DLC films.

The concentration of acid is important in controlling the iron loss caused by the wear-corrosion processes in sulfuric acid. The wear behavior of iron in sulfuric acid is generally similar to the corrosion behavior of iron in sulfuric acid. However, the maximum wear rate in the wear-corrosion process is reached in the neighborhood of about a 30-percent sulfuric acid concentration, while the maximum corrosion rate in the corrosion process is reached at about a 50-percent concentration. This discrepancy can be related to the influence of the mechanical energy introduced by sliding. More specifically, mechanical action can cause chemical reactions to proceed much faster than they would otherwise. The maximum rate of wear in the wear-corrosion process corresponded to the maximum activity of sulfuric acid (i.e., the minimum $p H$ ) and the maximum concentration of active hydrogen ions. However, in the corrosion process ( $i . e$. , in the absence of mechanical action), the actual concentration of the acid near the corroding surface was lower.

In the second part of the work, the DLC films were shown to behave tribologically much like bulk diamond. In a dry nitrogen environment, a mechano-chemical reaction produces a substance, probably a hydrocarbon rich layer, which greatly decreases the coefficient of friction $(0.1$ to 0.01$)$. In a moist air environment, mechano-chemical interactions drastically reduce the wear life of OLC films and water vapor greatly increases friction. When a DLC film is thermally annealed at $700^{\circ} \mathrm{C}$ in vacuum, the annealed surface of the DLC film behaves like graphite. Like bulk graphite, the annealed OLC film 
needs a certain amount of water to show low friction. Even with the annealed DLC film, the wear life of a OLC film in moist air was reduced by a factor of 2 as compared with that in dry nitrogen.

Finally, as typically shown in both cases, the wear and friction of the materials are dependent on the mechano-chemical interactions influenced by the ambient atmosphere.

ACKNOWLEDGEMENT

The author wishes to thank Emeritus Professor G.W.P. Rengstorff, University of Toledo, and Ors. J.J. Pouch and S.A. Alterovitz, NASA Lewis Research Center, for their contributions to this paper.

\section{REFERENCES}

1. Rengstorff, G.W.P., Miyoshi, K., and Buckley, D.H.: ASLE Transactions, vol. 29 , no. 1, p. $43(1986)$.

2. Miyoshi, K. and Rengstorff, G.W.P: Corrosion, vol. 45, no. 4, p. 266 (1989).

3. Miyoshi, K., Pouch, J.J., and Alterovitz, S.A.: Plasma-Deposited Amorphous Hydrogenated Carbon Films and Their Tribological Properties. NASA TM-102379 (1989).

4. Fischer, T.E. and Tomizawa, H.: Interaction of Tribochemistry and Microstructure in the Friction and Wear of Silicon Nitride. Wear of Materials 1985 (ed., K.C. 'udema) ASME, p. 22 (1985).

5. Buckley, D.H.: Surface Effects in Adhesion, Friction, Wear, and Lubrication. Elsevier (1981).

6. Heinicke, G.: Tribochemistry. Hanser Verlag München Wien (1984).

7. Eyre, T.S.: Source Book on Wear Control Technology ceds. D.A. Rigney and W.A. Glaeser) American Society for Metals, p. 1 (1978). 
8. Parker, R.J. and Bamberger, E.N.: Lubrication Engineering, vol. 40, p. $299(1984)$.

9. Cunningham, J.S., Jr. and Morgan, M.A.: Lubrication Engineering, vol. 35, p. 435 (1979).

10. Enke, K., Dimigen, H., and Hubsch, H.: Appl. Phys. Lett. 36 (4), p. 291 (1980).

11. Dimigen, H., Hubsch, H., and Memming, R.: Appl. Phys. Lett. 50 (16), p. $1056(1987)$.

12. Savage, R.H.: J. Appl. Phys. 19, p. 1 (1948).

13. Lancaster, J.K.: Wear 34, p. 275 (1975).

14. Bisson, E.E.: Nonconventional Lubricants, in Advanced Bearing Technology (eds., E.E. Bisson and W.J. Anderson), NASA SP-38, pp. 203-258 (1965).

15. Pepper, S.V.: J. Vacuum Sci. Technol., 20, p. 643 (1982).

16. Zaidi, H., Mezin, A., Nivoit, M., and Lepage, J.: Applied Surface Science, 40 , p. $103(1989)$.

17. Fontana, M.G. and Greene, N.D.: Corrosion Engineering, Second Ed., McGraw Hill Book Co. (1978).

18. Tomashov, N.D.: Theory of Corrosion and Protection of Metais, Translated and edited by B.H. Tytell, I. Geld, and H.S. Preiser, Macmillan (1966).

19. Rengstorff, G.W.P., Miyoshi, K., and Buckley, D.H.: Friction and Wear of Iron in Corrosive Media, NASA TP-1985 (1982).

20. Producers Handbook: Huntington Alloys, Resistance to Corrosion. The International Nickel Co., Inc., 1965, revised 1970.

21. Pouch, J.J., Warner, J.D., Liu, D.C., and Alterovitz, S.A.: Thin Solid Films, 157, p. 97 (1988). 
22. Pouch, J.J., Alterovitz, S.A., Warner, J.O., Liu, D.C., and Lanford, W.A.: Optical Properties of Hydrogenated Amorphous Carbon Films Grown from Methane Plasma. NASA TM-86995 (1985).

23. Field, J.E. (ed.): The Properties of Diamond. Academic Press, New York (1979).

24. Orzeszko, S., et al.: J. Appl. Phys. 64 (8), p. 4175 (1988).

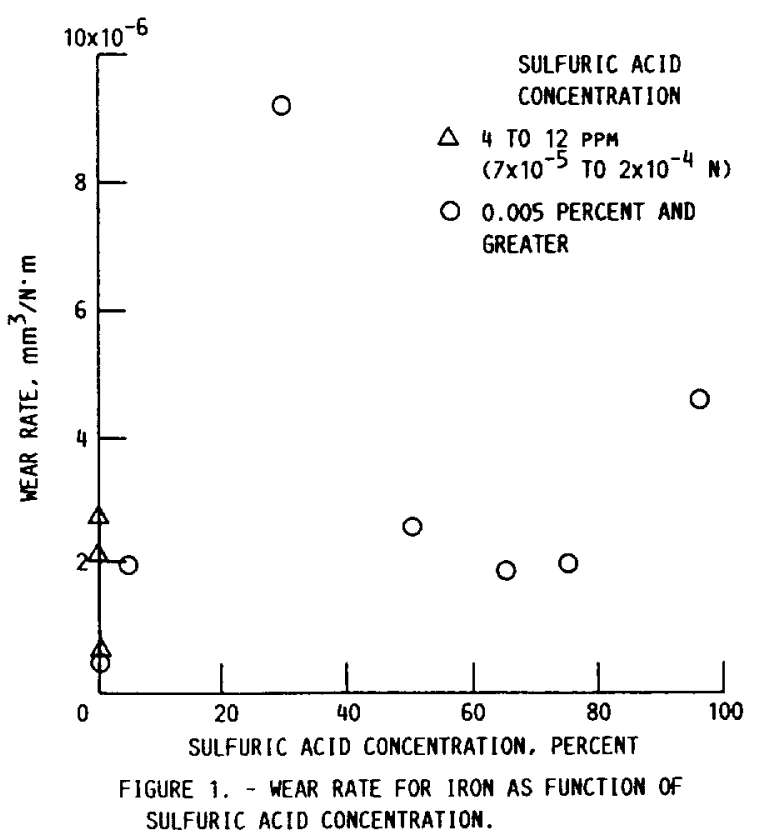




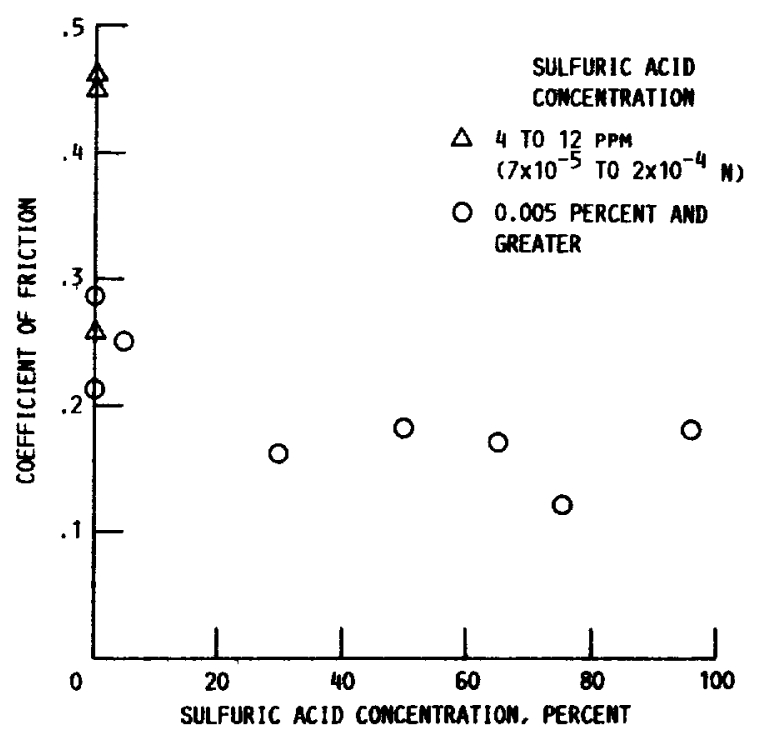

FIGURE 2. - COEFFICIENT OF FRICTION FOR IRON AS FUACTION OF SULFURIC ACID CONCEMTRATION.

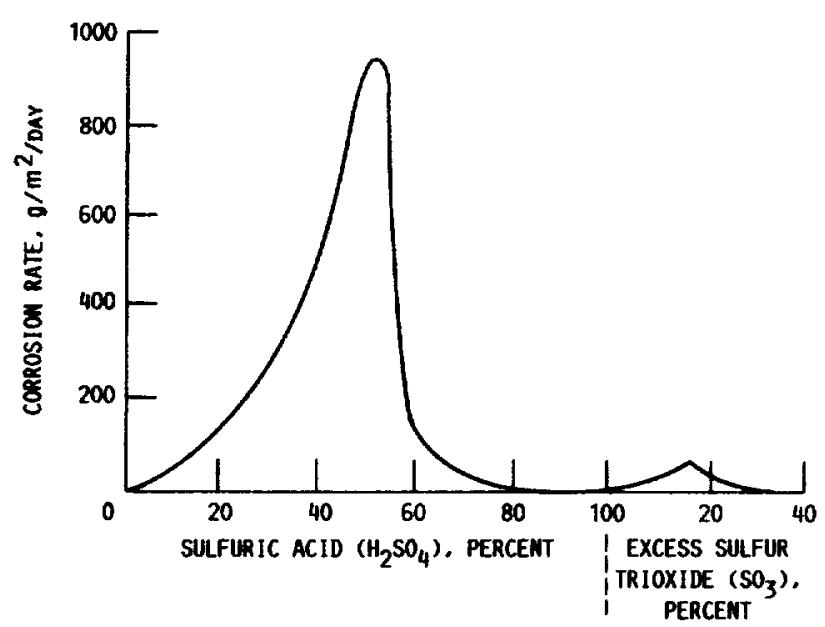

FIGURE 3. - DEPEMDENCE OF THE DISSOLUTION RATE OF IRON ON THE CONCERTRATION OF SULFURIC ACID AT $20^{\circ} \mathrm{C}[18]$.

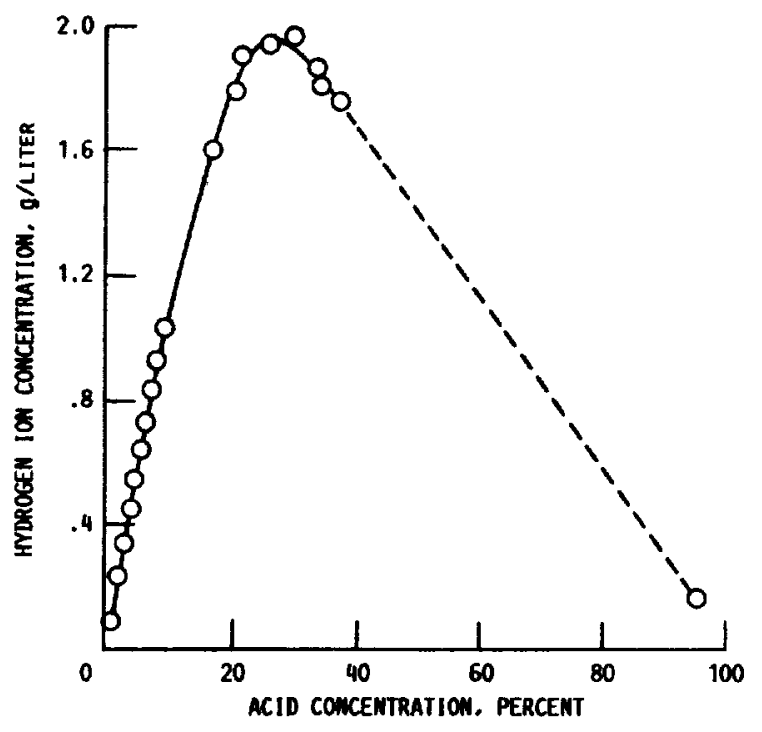

FIGURE 4. - CONCENTRATION OF HYDROGEN IONS IN AQUEOUS SOLUTIONS OF SULFURIC ACID $[18,20]$. 


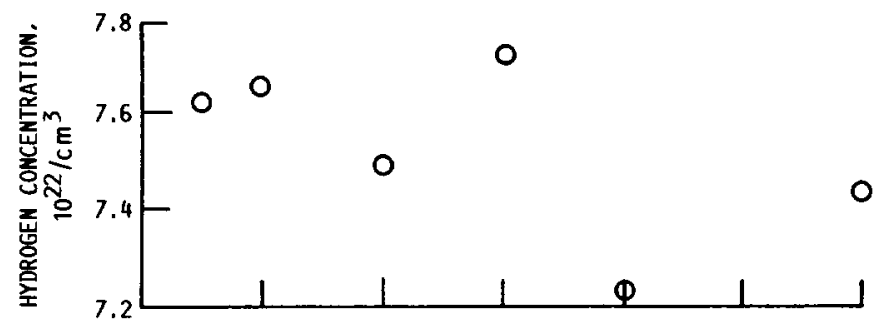

(a) HYDROGEN COMCENTRATION.

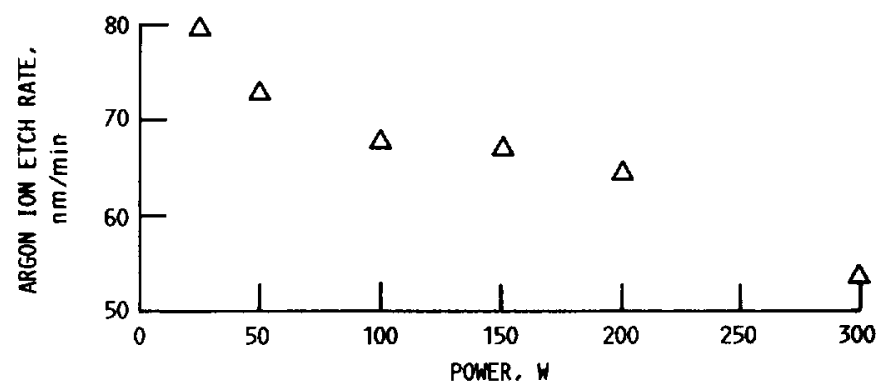

(b) ARGON ION ETCH RATE.

FIGURE 5. - HYDROGEN CONCENTRATION AMD ARGON ION ETCHING RATE AS FUMCTIONS OF DEPOSITION PONER FOR DLC FILM.

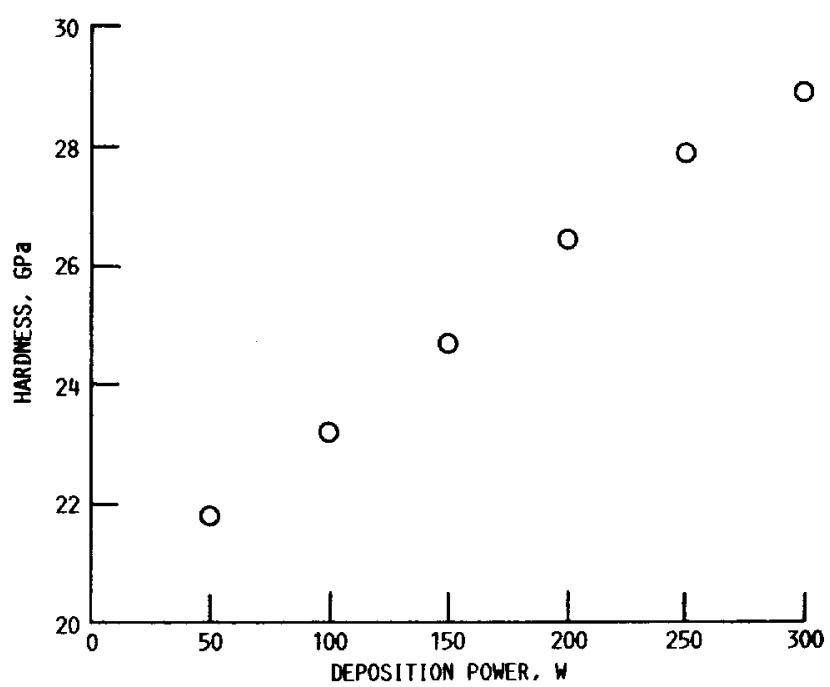

FIGURE 6. - VICKERS HARDNESS AS FUNCTION OF DEPOSITION POWER FOR DLC FILM DEPOSITED ON SILICON NITRIDE CHARDMESS MEASURING LOAD, $0.25 \mathrm{~N}$; HARDNESS OF SILICON NITRIDE SUBSTRATE, $17.1 \mathrm{GPa}$ ).

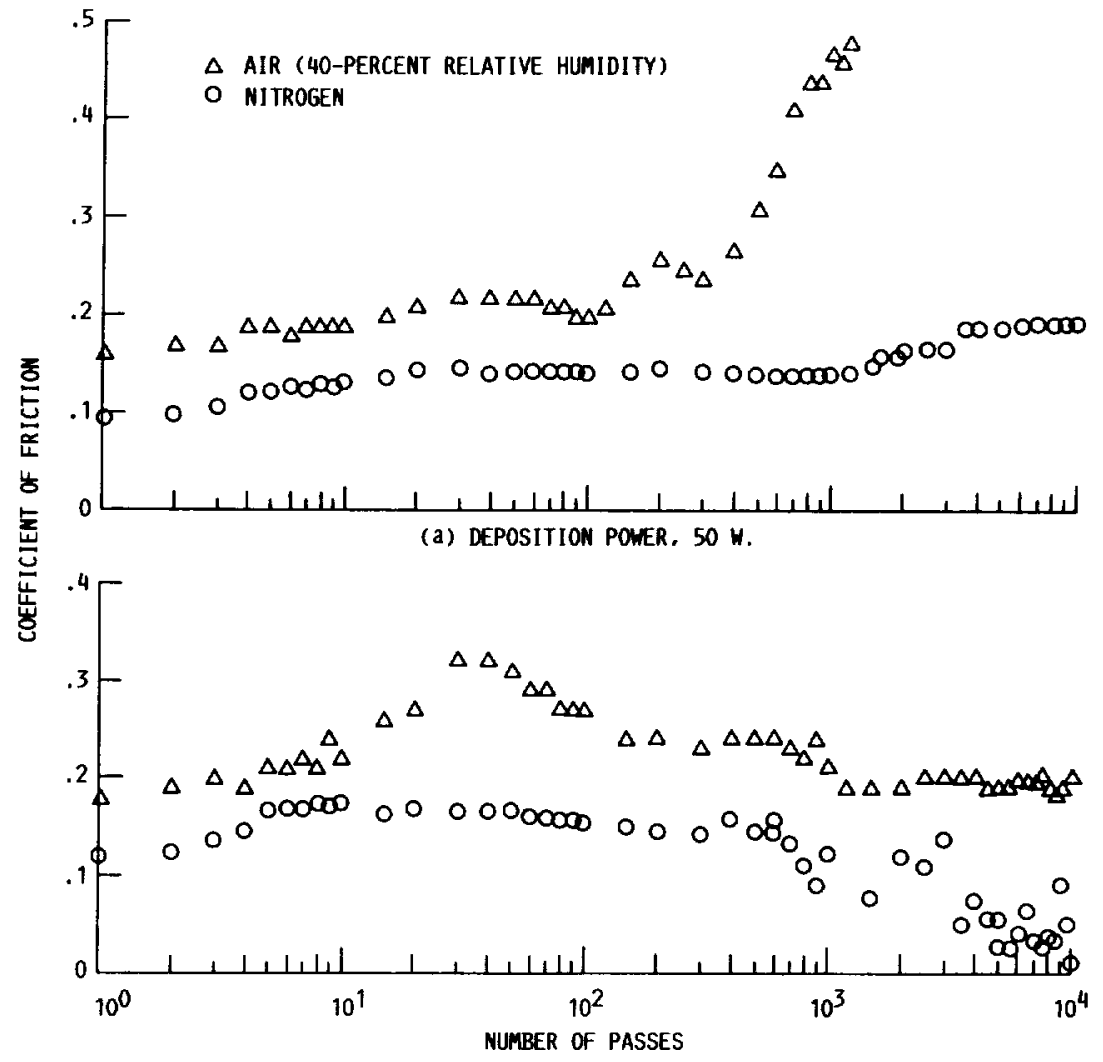

(b) DEPOSITION POMER, $250 \mathrm{~W}$.

FIGURE 7. - AVERAGE COEFFICIENT OF FRICTION AS FUNCTION OF MUMBER OF PASSES OF SILICON NITRIDE RIDER ACROSS DLC FILM SURFACE IN LABORATORY AIR AND IN DRY NITROGEN AT DEPOSITION POUERS OF 50 AND $250 \mathrm{~W}$ 


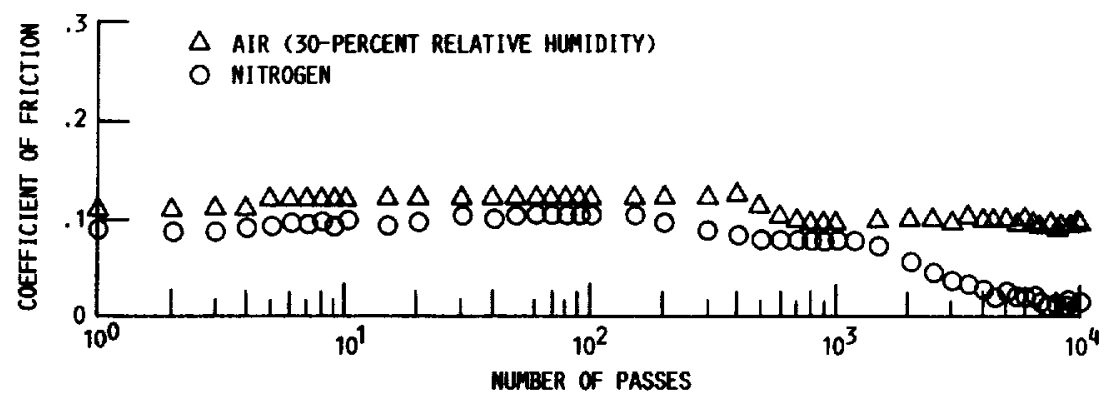

FIGURE 8. - AVERAGE COEFFICIENT OF FRICTION AS FUNCTION OF MUMBER OF PASSES OF SILICON MITRIDE RIDER ACROSS SIMGLE-CRYSTAL DIAMOND \{111\} SURFACE IN LABORATORY AIR AND IN DRY NITROGEN.

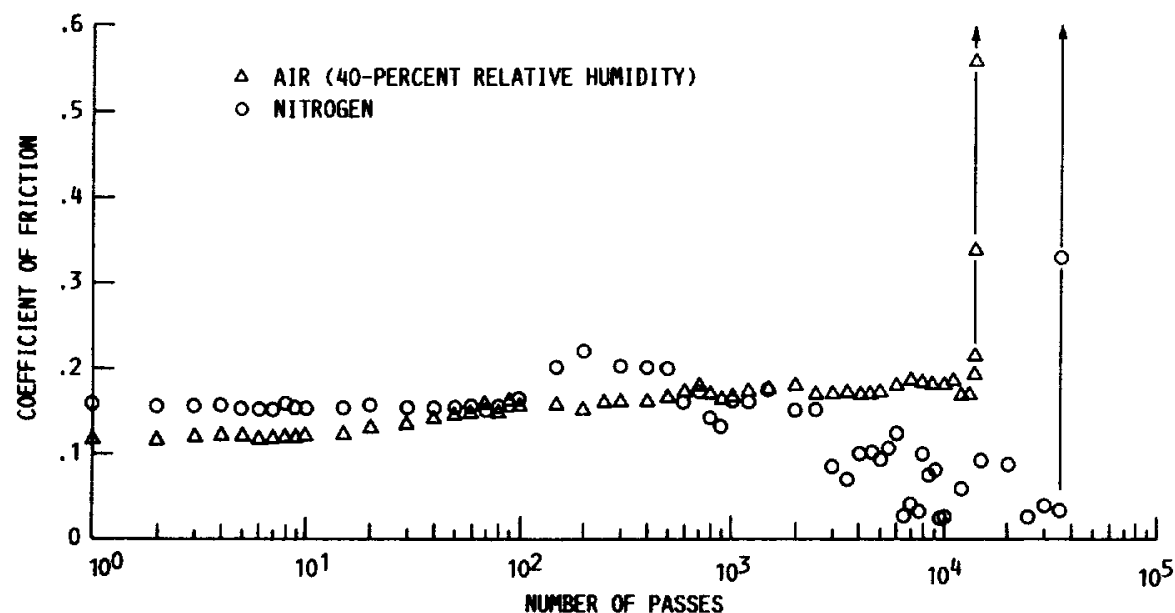

FIGURE 9. - AVERAGE COEFFICIEMT OF FRICTION AS FUNCTIOH OF MUMBER OF PASSES OF SILICON MITRIDE RIDER ACROSS DLC FILM SURFACE IN LABORATORY AIR AND IN DRY NITROGEN AFTER AMNEALIMG DLC IN VACUUUN AT $700{ }^{\circ} \mathrm{C}$ AMD AT DEPOSITION POHER OF $300 \mathrm{~W}$ 


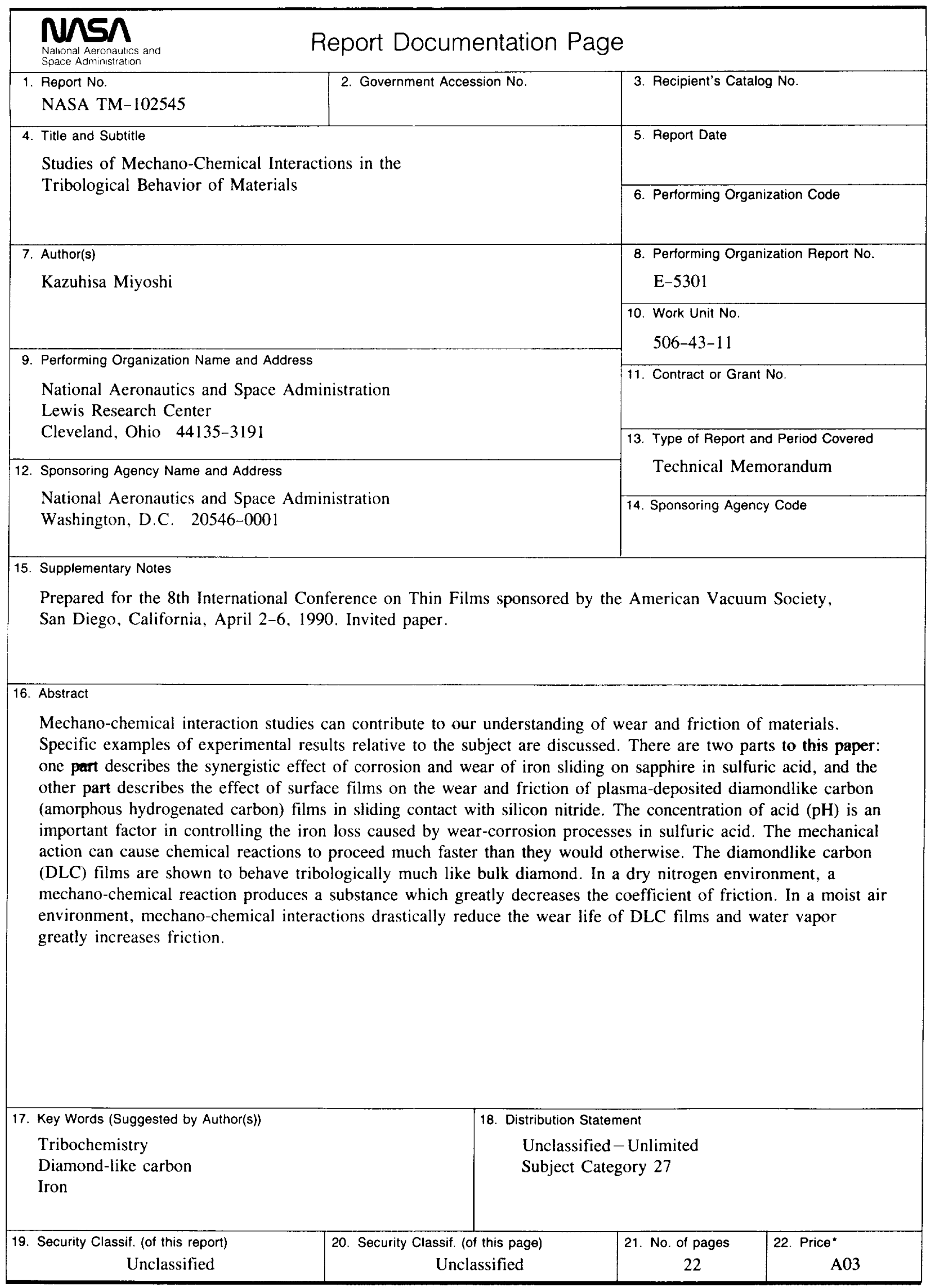

